\title{
Tissue Sparing Surgery and Its Relevance within Hip Prosthesis
}

\author{
T. Villa*, F. Pipino, A. Corradi \\ Policlinico di Monza, Monza, Italy \\ Email: maddoc83@gmail.com
}

Received 18 June 2014; revised 29 July 2014; accepted 14 August 2014

Copyright (C) 2014 by authors and Scientific Research Publishing Inc.

This work is licensed under the Creative Commons Attribution International License (CC BY). http://creativecommons.org/licenses/by/4.0/

c) (i) Open Access

\section{Abstract}

The total hip replacement rationale, since 1960 when it was introduced by Sir Charnley, has been modified and evolved until nowadays thanks to laboratory research and clinical trials. This evolution followed a guideline whose milestones are: 1) the surgical approach and implantation technique (ex: detachment of the greater trochanter); 2) to use or not to use cement; 3) the evolution of materials (titanium, ceramic, $x$-linked polyethylene); 4) the identification of the debris-disease rather than the cement-disease; 5) studies focused on bone-prosthesis interaction and biological phenomena related. Between those studies, the authors consider crucial the introduction of tissue sparing surgery and femoral neck preserving rationale, concepts to which they have devoted their scientific research and clinical experience for over the last 30 years, from 1980 to nowadays.

\section{Keywords}

Hip Prosthesis, Tissue Sparing Surgery (TSS), Femoral Neck Preserving (CFP), Mini-Prosthesis

\section{Introduction}

Tissue Sparing Surgery is a "surgical philosophy" referring to a maximum respect for SOFT TISSUES and BONE [1].

The concept of "the bone preserving and the respect for the articulation anatomy and biomechanics" which globally involved all the Orthopaedic Surgery becomes what we named "tissue sparing surgery" (T.S.S.). It was introduced during that period following the innovative concepts which evolved until today:

1) The prosthesis must integrate into the natural joint and must not substitute it.

2) Only pathologic tissues are removed while healthy tissues are spared.

3) Cortical bone is the strongest structure to obtain the primary stability of prosthesis.

\footnotetext{
"Corresponding author.
} 
4) The "cancellous bone" is the most important structure to achieve the bone ingrowth, but at the same time it is an important structure to obtain the primary stability of the prosthesis. We proposed the cancellous bone compression around the stem.

5) The "stress distribution" from the prosthesis to the bone takes place basically from the "path" systems of the cancellous bone which connects it with the cortical bone. Thus we will have a pattern of distribution of mechanical stresses close to the natural one, conditioning the biological answer of "bone remodelling", optimizing the bone-prosthesis interaction (Figure 1 and Figure 2) [2].

Same surgical approaches and techniques are revised by T.S.S. philosophy [3].

The prostheses have been modified to spare bone-stock: Mini-Prostheses. The main features of mini-prosthesis according to the the key parameters for the total hip prosthesis implant are:

1) Primary stability (with maximum adhesion to the bone) which comes first and influences the secondary stability achieved by "periprosthetic osteogenesys", leading to prosthesis integration through osteoinduction and osteoconduction (Figure 1 and Figure 2) [2].

2) Stresses distribution induced by the prosthesis integrated in the physiological system of distribution of load will affect the bone remodeling, through the biological answer to the mechanical stresses (Wolf's Law, Figure 3).

In particular, mini-prosthesis has the following key features:

1) Maximum conservation of the bone stock will improve the interaction between bone and prosthesis and the restoration of hip biomechanics, and furthermore will ease the potential revision.

2) Femoral neck preserving [5].

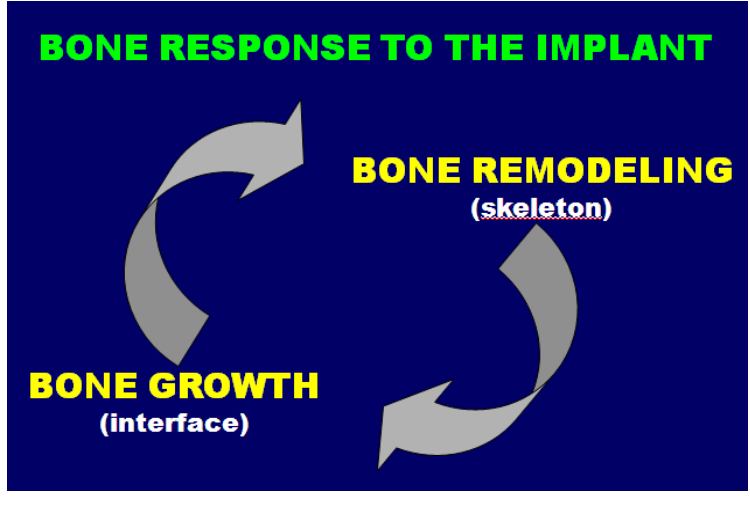

Figure 1. Bone response to the implant occurs through two mechanisms: the bone-integration in the early months followed by bone-remodeling throughout the life of the prosthesis as shown in the figure.

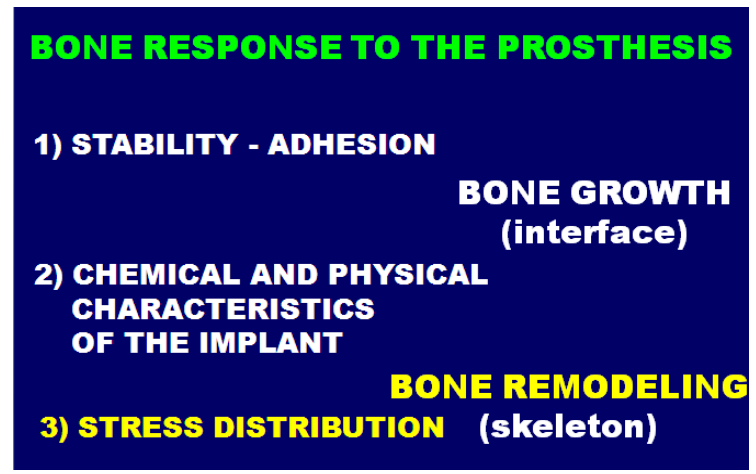

Figure 2. Bone response to the prosthesis-main factors of the response to the prosthesis: Points 1 and 2 show the most important factors of bone growth and step three (in yellow), the main factor of bone remodeling that is, the distribution of load stresses. 
3) Maximum respect for the soft tissues will decrease the surgical trauma and will improve the post-surgery and functional recover [1] [2].

Why preserving femoral neck in hip arthroplasty?

Femoral neck is usually not involved in pathological aspects of osteoarthritis and is the strongest structure [6] of the proximal third of the femur, a real "pivot" in the distribution of the stresses (Figure 4).

"Femoral neck preserving" allows the restoration of natural OFF-SET (Figure 3) and therefore the load

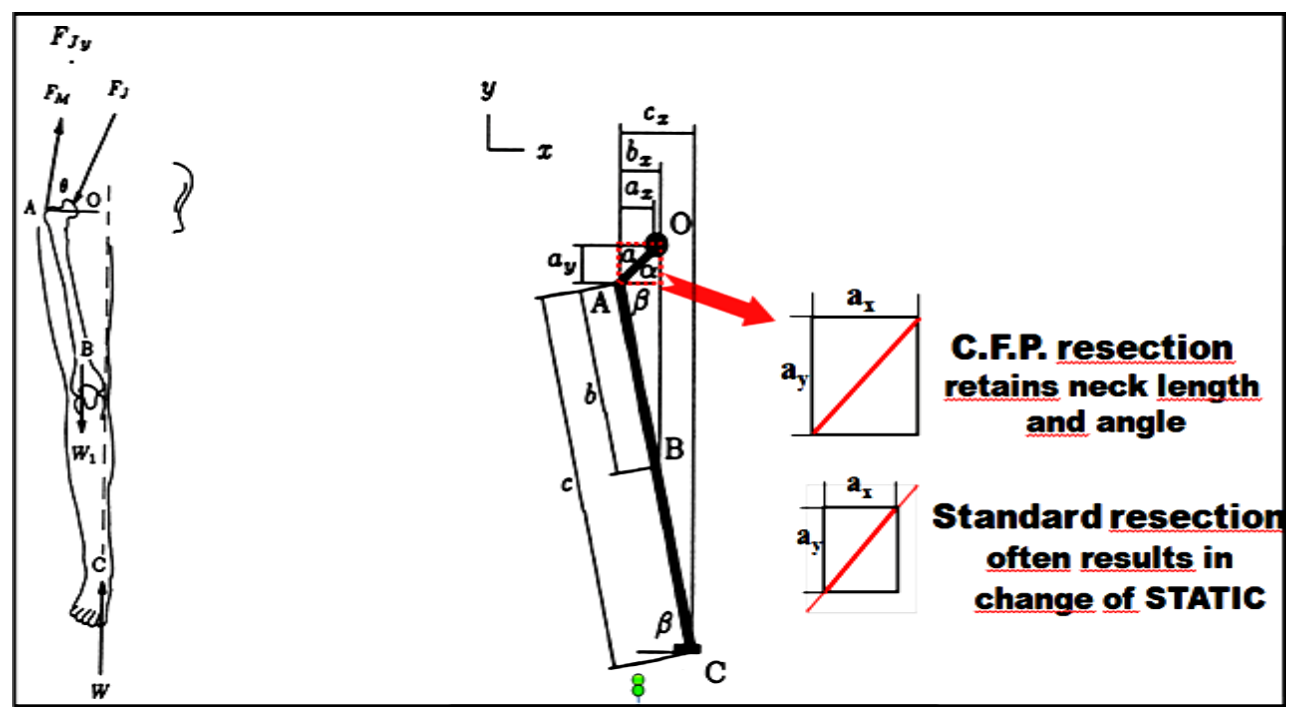

Figure 3. The importance of neck preserving in "free body diagram of the leg” [4]: O (center of rotation), A insertion of the gluteus medius, which marks the lever arm (Fm); F1 is the resultant of the loads with its $16^{\circ}$ angle of incidence respect to the axis of mechanical loads $(\mathrm{C}, \mathrm{W}), \mathrm{B}$ axis of mechanical loads. The OA distance is the lever arm outside Pauwels balance diagram. The AO value is increased preserving the femoral neck, in comparison to the one obtainable from a standard resection, so the diagram of the loads is more favorable. Femoral neck preserving allows the restoration of natural OFF-SET and therefore load distribution is mantained and reducing wear debris.

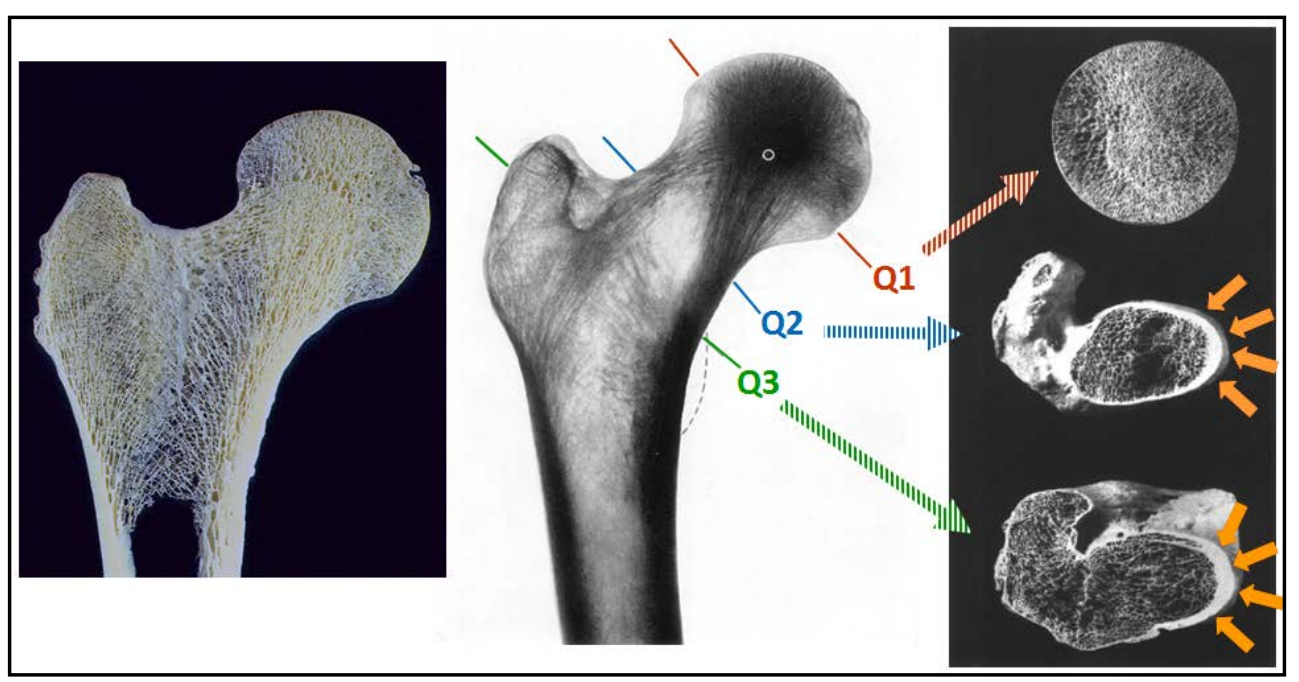

Figure 4. Head, neck and calcar section: It is clear that preserving the femoral neck at Q2 we obtain a complete ring of cortical bone, while going down in Q3 only the cortex of the medial part of the femour neck (calcar), while the remaining bone is cancellous. The situation highlighted in Q2 is the ideal one for the immediate stability of the implant and the concentration and distribution of loads. It extends to Q1 until isthmus of the neck (the more restricted region of the neck, where there is the confluence of the two truncated opposite cone). 
distribution is maintained reducing wear and debris [7]. The advantages are: Stress distribution along physiological lines towards the calcar and the great trocanther, maximum primary stability especially torsional, the recovery of natural hip biomechanics and the conservation of bone stock to achieve an advantage in the revision surgery (Figure 5).

Neck survives to the implant of the prosthesis only if the surgical technique doesn't damage the circumflex circulation (especially the posterior circumflex artery).

The historical evolution of the femoral neck preserving prosthesis from "Biodinamica" to C.F.P. and from the "Biequatorial Cup" to the T.O.P started since 1983. Some/many features of the C.F.P. stem (1996), designed for neck preserving, are still actual and optimal [8] [9].

The biequatorial CUP T.O.P. (Trabecular Oriented Pattern) allows respecting the acetabular subcondral cancellous bone and the acetabular bone directional systems. It comes from the idea of dissociating the inner equator from the outer equator of the cup (1977). This will allow implanting the cup in the acetabulum with an inclination similar to the physiological one $\left(50^{\circ}+\backslash-5^{\circ}\right)$, but at the same time the inner equator will be more horizontal $\left(30^{\circ}+\backslash-5^{\circ}\right)$ which is mandatory to avoid the dislocation and to distribute the loads along the "resultant R" of the forces (Figure 6).

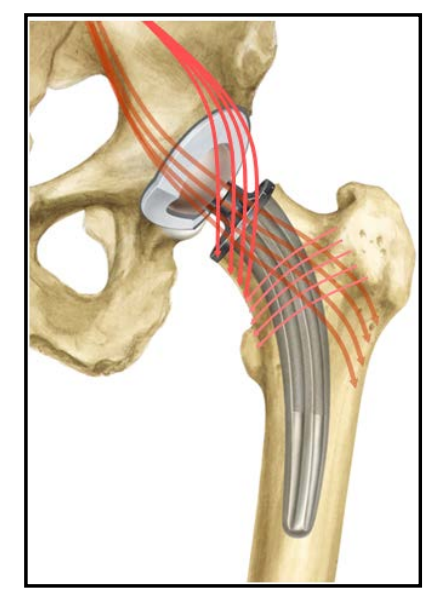

Figure 5. Stress distribution in CFP prosthesis throught the calcar and great trochanter according to physiological load.

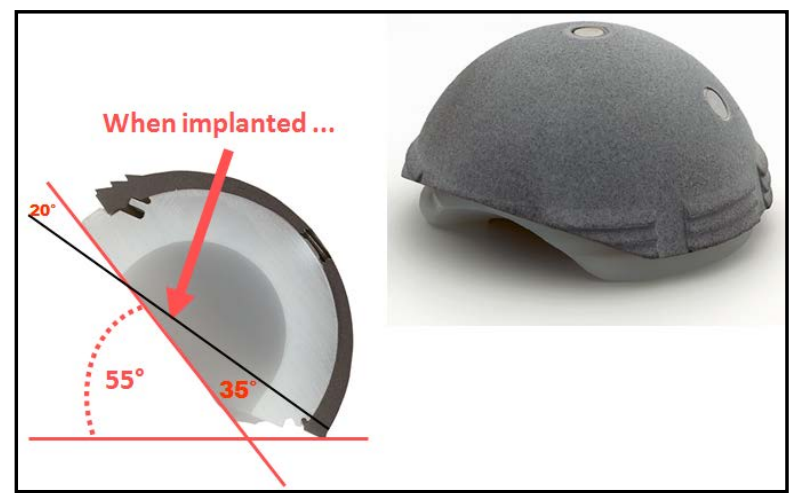

Figure 6. TOP cup. The image shows the $20^{\circ}$ dissociation between the equator of the outer surface compared to the equator of the internal cavity. This allows implanting the cup up to $55^{\circ}$ of tilt, as in natural acetabulum, with an orientation of the internal cavity to $35^{\circ}$ compared to the vertical loads. In this way, we obtain a greater coverage of the prosthetic head, decreasing the possibility dislocation of the prosthesis and the center of rotation is medialized keeping it in the center of the ileum bone. 


\section{Conclusion}

T.S.S. is a rational that must lead our surgical technique to the respect and saving of soft tissue and bone, optimizing of the bio-mechanic of the hip using mini implants and not lead us to make a "blind surgery" to show its less invasive technique, neglecting some technical details that can affect the surgical results. Long-term results have validated the rationale we exposed in our opinion. TSS: Through 25 years experience with femoral neck preserving in hip arthroplasty, we validated its rationale obtaining a survival curve near to 98\% [10] [11].

\section{References}

[1] Pipino, F. (2006) Tissue Sparing Surgery (T.S.S.) in Hip and Knee Arthroplasty. Journal of Orthopaedic Trauma, 7, 33-35. http://dx.doi.org/10.1007/s10195-006-0119-8

[2] Pipino, F. (1994) Interazione Osso-Protesi. Atti LXXIX SIOT, Giorn Ital Ortop Traumatol, 20, 121-129.

[3] Pipino, F. (2013) Lateral Direct Aproch to the Hip Modified in Hip Prosthesys. Journal of Orthopaedics and Traumatology, 14.

[4] Ozkaya, N., et al. (1999) Fundamentals of Biomechanics, Equilibrium, Motion and Deformation. 2nd Edition, 102103.

[5] Pipino, F. (2004) CFP Prosthetic Stem in Mini-Invasive Total Hip Arthroplasty. Journal of Orthopaedics and Traumatology, 4, 165-171. http://dx.doi.org/10.1007/s10195-004-0065-2

[6] Tobin, W.J. (1955) The Internal Architecture of the Femour and Its Clinical Significance. The Journal of Bone and Joint Surgery. American Volume, 37, 41-57.

[7] Devane, A. and Horne, J. (1999) Assessment of Polyethylene Wear in Total Hip Replacement. Clinical Orthopaedics and Related Research, 369, 59-72. http://dx.doi.org/10.1097/00003086-199912000-00007

[8] Pipino, F. and Calderale, P.M. (1987) La protesi biodinamica totale d'anca. The Italian Journal of Ortophaedics and Traumatology, 13, 289-297.

[9] Pipino, F. and Calderale, P.M. (1983) A Biequatorial Cup. Panminerva Medica, 25, 231-239.

[10] Pipino, F., Molfetta, L. and Grandizio, M. (2000) Preservation of the Femoral Neck in Hip Arthroplasty; Results of a 13 to 17 Year Follow-Up. The Italian Journal of Ortophaedics and Traumatology, 1, 31-39. http://dx.doi.org/10.1007/s101950070026

[11] Pipino, F. and Keller, A. (2006) Tissue Sparing Surgery: 25 Years’ Experience with Femoral Neck Preserving Hip Arthroplasty. Journal of Orthopaedic Trauma, 7, 36-41. http://dx.doi.org/10.1007/s10195-006-0120-2 
Scientific Research Publishing (SCIRP) is one of the largest Open Access journal publishers. It is currently publishing more than 200 open access, online, peer-reviewed journals covering a wide range of academic disciplines. SCIRP serves the worldwide academic communities and contributes to the progress and application of science with its publication.

Other selected journals from SCIRP are listed as below. Submit your manuscript to us via either submit@scirp.org or Online Submission Portal.
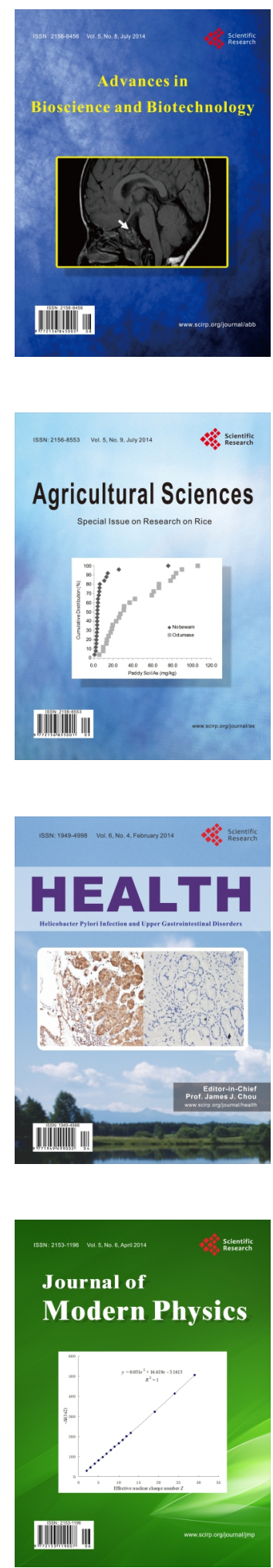
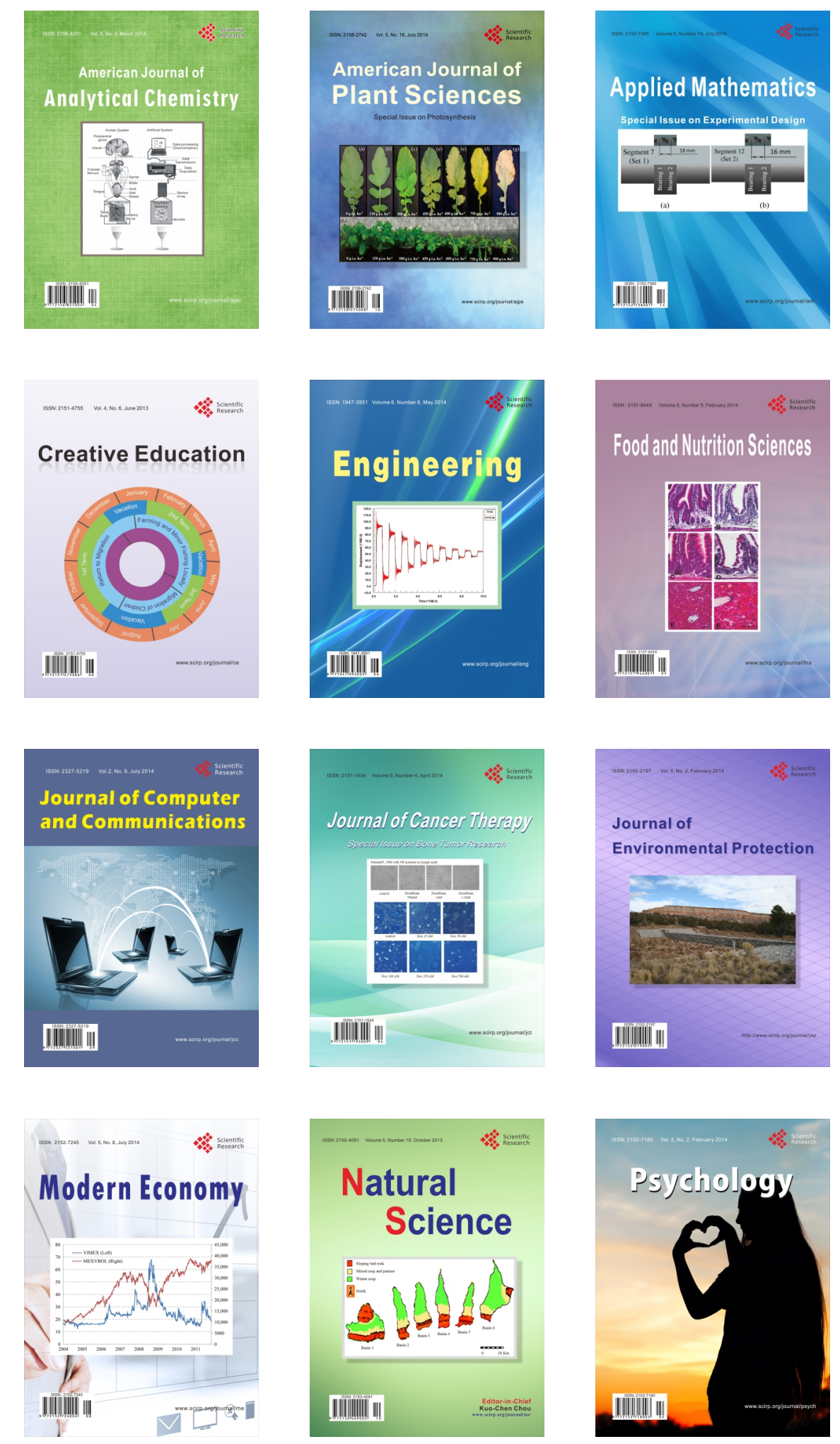